\title{
Exploring Mediterranean languages learners' motivational profiles
}

Ioannis Galantomos

Department of Mediterranean Studies, University of the Aegean, Greece

https://doi.org/10.36505/ExLing-2012/05/0014/000220

\begin{abstract}
The aim of this study is to report the results of a survey we carried out in order to explore the role of motivation in learning particular Mediterranean languages, namely, Arabic, Hebrew and Turkish in an academic setting. Second language acquisition is contingent on various factors, such as age, gender, personality, learning strategies and motivation. Among these variables, motivation influences significantly the rate and final outcome of learning a second language. In order to describe the motivational profiles of 30 university students learning Arabic, Hebrew and Turkish as foreign languages we conducted a small-scale experiment. Our findings indicate the prevalence of instrumental over integrative motivation.
\end{abstract}

Key words: SLA, motivation, Mediterranean languages

\section{Introduction}

In the field of Second Language Acquisition (SLA), it is undeniable that certain people are more successful language learners than others. Applied linguists have tried to develop a comprehensive typology of individual differences which are deemed to influence SLA (Bialystok and Hakuta 1994). The factors that contribute to individual differences are divided into three main categories, namely, cognitive factors, such as intelligence and aptitude, affective factors, such as motivation and attitude and personality factors, such as extroversion and introversion (Johnson 2001).

Among the above mentioned individual differences motivation has been accepted by both instructors and learners as one of the key factors which exert an influence on the final outcome of learning a second language (Dörnyei 1998). Motivation is a multifaceted phenomenon and generally refers to the attitudes and affective states which influence the degree of effort made by language learners (Ellis 1997).

In the relevant literature, four major types of motivation have been identified, namely, instrumental (language learning for a particular functional reason, such as better professional prospects), integrative (interest in the people and culture expressed by the target language), resultative (motivation seen as a result of learning) and intrinsic motivation (curiosity for second language learning rather than general reasons per se) (Ellis 1985, 1997). These four motivational types should be seen as complementary rather than oppositional (Ellis 1997). Looking closer at this classification, it is clear that more tangible and

ExLing 2012: Proceedings of 5th Tutorial and Research Workshop on Experimental Linguistics, 27-29 August 2012, Athens, Greece 
measurable motivational types are the first two ones, namely, instrumental and integrative motivation. For this reason, the emphasis of this study was laid on the investigation of these two types.

In light of the above, we conducted a small-scale experiment in order to investigate the motivational profiles of Greek university students learning Arabic, Hebrew and Turkish in a foreign language context.

\section{Method}

\section{Participants}

Our study consisted of 30 advanced Greek students who learn Arabic, Hebrew and Turkish as foreign languages in the Department of Mediterranean Studies (DMS) at the University of the Aegean (Rhodes campus). They were divided into three groups of 10 students according to the foreign language learnt, each group containing students learning one of the languages mentioned above. Regarding our participants' sex, 9 were males and 21 females. Their mid age was 22.3 years old.

\section{Materials and procedure}

The data on motivational profiles were collected through adopting and adapting an existing questionnaire consisting of 8 statements (the questionnaire is available upon request). Out of these 8 statements, items 2, 3, 4 and 6 showed instrumental motivation, whereas the remaining items $1,5,7$ and 8 showed integrative motivation. The original questionnaire has already been used in similar studies (cf. Gardner 1985). Our participants' task was to indicate on a three-type scale (i.e. 1: disagree, 2: neutral and 3: agree) to what extend they agree or disagree with these 8 statements.

The questionnaire was administered to all students enrolled on advanced Arabic, Hebrew and Turkish classes in April 2012. The researcher, after being introduced by the instructor, explained the goal of the study and provided detailed instructions on how to fill in the above mentioned questionnaire. The whole procedure lasted for approximately 20 minutes. The data were analyzed by means of SPSS for Windows and the statistical criterion $\mathrm{x}^{2}(\mathrm{p}<0.05)$ was used to examine the statistical significance of our findings.

\section{Data analysis}

Our results indicate the prevalence of instrumental over integrative motivation. This finding is evident across the three languages. In other words the majority of our subjects reported that they have chosen to study Arabic, Hebrew and Turkish in order to improve their career prospects rather than having a better understanding of the people and their culture (Arabic: 7 out of 10, Hebrew: 6 out of 10 and Turkish: 9 out of 10) $(\mathrm{p}<0,05)$. 
Exploring Mediterranean languages learners' motivational profiles

\section{Discussion and Conclusions}

Our findings (i.e. prevalence of instrumental motivation over integrative one) can be attributed to the context of learning Arabic, Hebrew and Turkish. Learning the target language in an SLA context forces the learner to learn it as well as possible. On the other hand, the objective of learning the target language in a foreign context is a good working knowledge for better professional potentials (Dörnyei 2001).

The three languages in our study are studied in an institutional/academic setting. Hence, there is no real and actual need for communication in the target language outside classroom. Apart from the context, Gardner (2001) mentions two major assumptions within the concept of integrative motivation which provide further justification for our findings. First, the ultimate goal of SLA is near-native competence. Second, the above mentioned educational goal requires identification with the second language community. At this point it should be mentioned that the tendency to approach language learners as potential approximations to native speakers and measure their achievements against those of monolinguals is controversial and a cause of fuzziness for two main reasons. Firstly, it takes for granted that the notion of the native speaker is straightforward and therefore easily defined and secondly that there is an ideal native speaker, which is not the case by no means (for a detailed discussion cf. Andreou and Galantomos 2009). Under this perspective and taking into consideration the nature and the requirements of foreign language teaching in the DMS, it becomes clear why the major driving force behind choosing and studying a foreign language is to gain better career prospects and not to understand the culture of the people who speak the languages in question.

Our findings are in line with those reported in similar surveys, such as Michalakis (2011), Coleman (1996), Dörnyei (1990) and Gardner and Lambert (1972). Moreover, the learning context (foreign vs second) seems to affects learners' choices in relevant aspects, such as the adopted learning strategies when dealing, for example, with unknown vocabulary (preference for formal learning strategies over informal or spontaneous ones) (e.g. Galantomos 2011).

A number of limitations of the present study are noteworthy. First, the small sample prevents us from reaching safer conclusions. Second, the proportion of our subjects (more females than males) does not enable us to gain more insights regarding the role of gender in certain choices. Third, the focus on advanced learners does not give us the opportunity to explore potential shifts in motivation from level to level. Finally, more data are required from learners who study a language in a second language context so as to make the necessary comparisons and investigate in a more detailed way the role of setting/context in motivation. 
To sum up, in this study we investigated the motivational profiles of advanced university students learning Arabic, Hebrew and Turkish in an institutional setting. Our findings are related to the role of the learning setting (foreign vs second) and demonstrate the prevalence of instrumental over integrative motivation.

\section{References}

Andreou, G. and Galantomos, I. 2009. The Native Speaker Ideal in Foreign Language Teaching. Electronic Journal of Foreign Language Teaching 6(2), 200208.

Bialystok, E. and Hakuta, K. 1994. In other Words. The Science and Psychology of Second-Language Acquisition. New York, Basic Books.

Coleman, J.A. 1996. Studying languages: a survey of British and European students. London, CILT.

Dörnyei, Z. 1990. Conceptualizing Motivation in Foreign-Language Learning. Language Learning 40, 45-78.

Dörnyei, Z. 1998. Motivation in second and foreign language learning. Language Teaching 31, 117-135.

Dörnyei, Z. 2001. Teaching and Researching Motivation, London, Longman.

Ellis, R. 1987. Understanding Second Language Acquisition. Oxford, OUP.

Ellis, R. 1997. Second Language Acquisition. Oxford, OUP.

Galantomos, I. 2011. Vocabulary learning strategies among advanced Turkish learners. In Botinis, A. (ed.) 2011, Proceedings of the fourth ISCA Tutorial and Research Workshop on Experimental Linguistics, 75-78. Athens, University of Athens.

Gardner, R.C. 1985. Social Psychology and Second Language Learning. Theories of Attitudes and Motivation. London, Edward Arnold.

Gardner, R.C. 2001. Integrative and Second Language Acquisition. In Dörnyei, Z. and Schmidt, R. (eds.) 2001, Motivation and Second Language Acquisition, 1-19. Honolulu, National Foreign Language Resource Center.

Gardner, R.C. and Lambert, W. 1972. Attitudes and Motivation in Second Language Learning. Rowley, MASS, Newbury House.

Johnson, K. 2001. An Introduction to Foreign Language Learning and Teaching. Harlow, Longman.

Michalakis, A. 2011. Comparative study of language learning motivation in the South Eastern Mediterranean languages. Unpublished Senior Thesis. Rhodes, University of the Aegean. 